\title{
Intimate Partner Violence in Pregnancy: Knowledge and Experiences of Pregnant Women and Controlling Behavior of Male Partners in Sokoto, Northwest Nigeria
}

\author{
Oche Mansur Oche $\mathbb{D}$, Habibullah Adamu, Aisha Abubakar, Munira Sahabi Aliyu, \\ and Abubakar Shehu Dogondaji
}

Department of Community Health, Usmanu Danfodiyo University, Sokoto, Nigeria

Correspondence should be addressed to Oche Mansur Oche; ochedr@hotmail.com

Received 22 July 2019; Revised 21 November 2019; Accepted 17 January 2020; Published 6 March 2020

Academic Editor: Hind A. Beydoun

Copyright (C) 2020 Oche Mansur Oche et al. This is an open access article distributed under the Creative Commons Attribution License, which permits unrestricted use, distribution, and reproduction in any medium, provided the original work is properly cited.

\begin{abstract}
Background. Violence against women perpetrated by an intimate partner is an important public health issue. In recent years, attention has focused also on intimate partner violence (IPV) during pregnancy due to its prevalence, adverse health consequences, and intervention potentials. Aim. To determine the knowledge, experiences, and factors influencing IPV, including the controlling behaviors of male partners of pregnant women attending an antenatal clinic (ANC) of a tertiary health facility in Sokoto. Materials and method. A descriptive cross-sectional study was conducted among 260 pregnant women attending ANC in a tertiary health facility in the Sokoto metropolis. They were selected using a systematic sampling technique, and a set of pretested questionnaire items was used for data collection. Data were analysed using IBM SPSS version 20. Results. The respondents' ages ranged from 19 to 40 years with a mean of $29.09 \pm 4.99$ years, and up to $83.5 \%$ of them were in a monogamous setting. Three-quarters of them were Muslims mostly from urban areas $(72.1 \%)$, and $36.4 \%$ had a university or HND degree. Majority of them responded correctly to questions on IPV; overall, up to $99.2 \%$ of them had good knowledge of IPV. About 33\% of the respondents have experienced IPV while pregnant and up to $61.7 \%$ of them said they did nothing because of fear. Some of the controlling behaviors of male partners included always asking for permission before seeing friends and family members and also controlling their finances. Factors associated with IPV include tribe, place of residence, and partner consuming alcohol. Conclusion. Majority of the respondents had good knowledge of IPV with about one-third of them ever experiencing it. Respondent's partners were mostly jealous and exhibited some form of controlling behaviors. Physical violence was the most prevalent form, and most of the victims did nothing about it. Government and women's right groups should push for the implementation of tougher punitive measures against perpetrators of IPV.
\end{abstract}

\section{Introduction}

Violence against women is a major public health and human rights concern, with intimate partner violence and sexual violence being among the most pervasive forms of violence against women [1]. Although women can be violent in relationships with men, the most common perpetrators of violence against women are male intimate partners or expartners [2]. Until recently, most governments have considered violence against women (particularly "domestic" violence by a husband or other intimate partner) to be a relatively minor social problem [3]. In recent times, however, violence against women is recognized as a global concern [3, 4]. Intimate partner violence (IPV) is defined as threatened, attempted, or completed physical or sexual violence or emotional abuse by a current or former intimate partner. It describes the physical, sexual, or psychological harm by a current or former intimate partner or spouse, and this type of violence can also occur among heterosexual or same-sex couples [4]. The World Health Organization (WHO) defines intimate partner violence as an act of coercion, physical abuse, or threat of violence in an intimate relationship [5]. 
According to WHO, IPV is the most common form of violence against women. Violence by an intimate partner is manifested by physical, sexual, or emotional abusive acts as well as controlling behaviors; although violence occurs in different forms and settings including the workplace, school, and community, violence at home by intimate partner violence is considered as the most prevalent form [6]. The act of physical violence includes slapping, kicking, pushing, and beating, as well as forced sexual intercourse and other forms of sexual coercion. Psychological abuse involves insults, belittling, constant humiliation, threats of harm, or controlling behaviors that consist of isolating a person from friends and families; monitoring their movements; and restricting access to financial resources, employment, education, or medical care [7].

Studies conducted in sub-Saharan African and Asian countries showed an IPV rate ranging from 28\% in Madagascar, $74 \%$ in Ethiopia, and $57 \%$ in India to $87 \%$ in Jordan [8]. In a multicountry study conducted in 10 different countries, a rate ranging from 18.5 to $75.8 \%$ was reported; domestic violence by an intimate partner alone had a rate of 15.5 to $70.9 \%$, while violence by nonpartners ranged between 5.1 and $64.6 \%$ [5]. In Nigeria, a study conducted in Lagos, Southwest Nigeria, on the prevalence and predictors of intimate partner violence exposure showed a one-year prevalence of $29 \%$, with significant proportions reporting psychological (23\%), physical (9\%), and sexual (8\%) abuse, while in Oyo, a study showed that there was a $31.1 \%$ prevalence of wife beating among women of reproductive age $[9,10]$. In Northern Nigeria, studies conducted among pregnant women in Zaria and Jos showed $28 \%$ and $63.2 \%$ of the respondents, respectively, experienced some form of abuse $[11,12]$.

Intimate partner violence in pregnancy has been identified among the leading causes of maternal mortality in some developed countries like the United States and the United Kingdom [13]. Pregnancy-related IPV has been reported to be associated with high perinatal and neonatal mortality risk among exposed women compared to unexposed pregnant women [14]. Neonatal complications include intrauterine growth retardation, preterm delivery, and low birth weight with extended intensive hospitalization [15-19].

Maternal consequences associated with IPV during pregnancy include abortions, miscarriages, preeclampsia, gestational diabetes, and placental abruption [20].

Although the prevalence of IPV is quite high in Nigeria, far fewer cases are reported. This is probably because of the influence of religion and culture especially in many parts of Africa, where culture may allow couples to solve their problem by the use of violence, since most cases of violence against an intimate partner are not seen as wrong. Nigeria still remains patriarchal in nature, where men are regarded as "gods" of the household, controlling every affair, including the women's right to reproductive capabilities [21]. Incidents are therefore, underreported because doing so is viewed as causing indignity to the husband and being disrespectful of family members and elders whose roles include arbitrating in such matters. As a result of this, the true magnitude of the problem is relatively unknown and unexamined [22-24].

Despite increasing research on the prevalence and health effects of IPV during pregnancy from numerous countries around the globe, several gaps in knowledge still exist especially in low- and middle-income countries including Nigeria [25]. Though several studies have been conducted on IPV globally, in Nigeria there is still dearth of information on IPV; most of the studies conducted looked at IPV among women generally, but not much studies had been carried out among pregnant women in Sokoto State despite its effect on the health of the mothers and their babies. Systematic reviews were conducted on domestic violence, which included studies done in different parts of the world; however, studies among pregnant women were not included in the review. The findings showed that relatively few studies and publications emerged from Africa compared to North America and Europe [26]. Furthermore, there are differences in cultural and religious patterns in the different zones in the country; even in the northern part of the country, there are differences in what people regard as IPV [27].

This study, therefore, is aimed at examining the knowledge of IPV, controlling behaviors of male partners, and experiences of intimate partner violence among women attending an antenatal clinic at the Usmanu Danfodiyo University Teaching Hospital, Sokoto.

\section{Materials and Method}

The study was conducted at the Usmanu Danfodiyo University Teaching Hospital (UDUTH), Sokoto between June and August, 2018. Being a tertiary institution, the hospital provides specialized health care service to Sokoto State, the entire northwestern region of the country, and the neighboring Niger Republic. With a bed capacity of 850, UDUTH has staff strengths of over 1705, which includes doctors, nurses, pharmacists, medical laboratory scientists, and physiotherapists spread across all departments providing curative, preventive, and rehabilitative services. Antenatal clinic service is provided on all the weekdays with an average daily attendance of 250 pregnant women.

The study employed a descriptive cross-sectional study design, and all pregnant women presenting at the ANC clinic for booking or routine antenatal care and must have had a previous pregnancy (inclusion criteria) constituted the study population. Respondents were recruited into the study using the formula for estimating sample size in a population less than 10,000 [28].

After adjusting for a nonresponse rate of $10 \%$, a total of 260 respondents were recruited into the study.

A systematic sampling technique was used to select the study participants after calculating the sampling interval as follows:

Sampling interval $(k)=$ number of pregnant women per booking clinic,

$$
\begin{aligned}
\text { Sample size } & =\frac{100}{264}, \\
K & =\frac{1}{3} .
\end{aligned}
$$


Based on the above sampling interval, the systematic sampling technique was carried out as follows:

(i) The first participant was selected using simple random sampling carried out among the first three pregnant women that came for booking

(ii) Thereafter, every third pregnant woman that came to the ANC clinic for booking was enrolled in the study until the required sample size was obtained. This was continued every day until the desired sample size was obtained

A set of pretested semistructured interviewer-administered questionnaire items was administered on the respondents which sought information on respondents' sociodemographic characteristics, their knowledge of IPV, the controlling behavior of partners during pregnancy, the experiences of respondents, and factors influencing IPV during pregnancy.

Data collection using the instrument described above was done with the help of three medical students who were trained by the researchers on the objectives of the study, general principles of research ethics, interpersonal communication, and techniques of data collection.

The data from the questionnaire was manually checked for completeness and entered into IBM SPSS version 20 for electronic data cleaning and analysis. Each correct response to a knowledge variable was awarded a score of one mark, and a zero mark was awarded to each incorrect response. The knowledge scores were added up, converted to percentage, and graded as either good knowledge (score of $\geq 50 \%)$ or poor knowledge $(<50 \%)$. Continuous variables were summarized as mean and standard deviation, and categorical variables were summarized and presented as frequencies and percentages. This was followed by inferential statistics (bivariate analysis), which were used to identify the major determinants of IPV during pregnancy. The level of statistical significance was set at $5 \%$ $(p<0.05)$.

Permission for the study was obtained from the ethics and research committee of UDUTH. Participants were informed of the objectives of the study and were assured of the confidentiality of the information volunteered. Informed verbal consent was also obtained from all the respondents.

\section{Results}

The respondents' ages ranged from 19 to 40 years with a mean age of $29.09 \pm 4.99$ years, and up to $83.5 \%$ of them were in a monogamous setting. Up to three-quarters of them were Muslims mostly from urban areas (190 $(72.1 \%)$ ), and $92(36.4 \%)$ had a university or HND and 96 (36.9\%) belonged to the upper socioeconomic class (SEC); for their partners, $170(65.4 \%)$ were in the upper SEC (Table 1).

Majority of the respondents (239 (92.3\%)) were aware of what intimate partner violence is, and a greater proportion of them $(102(39.2 \%))$ heard it from the media. Majority of them responded correctly to questions on IPV; overall, up to $258(99.2 \%)$ of them had good knowledge of IPV (Table 2 and Figure 1).

About one-third of the respondents (84 (32.3\%)) said they have to seek for their partners' permission before seeing friends and family, and partners controlled and monitored all their movements $(69(26.5 \%))$ and controlled their finances (28 (10.6\%)) (Figure 2).

The lifetime prevalence of IPV in pregnancy was $30.4 \%$ $(N=79)$ (Figure 3); a total of $26(32.9 \%)$ of the women experienced IPV in their first pregnancies, while $53(67.1 \%)$ of them occurred during their subsequent pregnancies. About two-thirds of the respondents said the IPV they experienced occurred frequently, and 44 (55.7\%) of them said it was less frequent during pregnancy than outside pregnancy. The most common forms of IPV were physical and sexual violence (62.70 and 57.30\%, respectively (Figure 4)). Other forms of IPV experienced by respondents include being insulted (78 (30\%)), being humiliated (61 (23.5\%)), and being forced to have sexual intercourse (39 (15\%)) (Table 3).

Regarding the reactions of respondents following the incidences, up to $46(61.3 \%)$ of them admitted doing nothing following IPV, mainly because of fear (35 (77.8\%)). Majority of the respondents $(236(90.8 \%))$ believed that IPV is associated with drugs and alcohol consumption, while 249 (95.8\%) of them were of the opinion that it is associated with exposure to violence between parents (Table 4).

Regarding factors associated with IPV during pregnancy, up to $31(62.0 \%)$ of those who are of the Yoruba tribe had experienced IPV, whereas only 25 (14.8\%) among the Hausa tribe experienced it; the relationship was statistically significant $\left(X^{2}=71.280, p<0.001\right)$. Similarly, more than half (39 $(55.7 \%))$ of those who lived in rural areas experienced IPV as against those living in urban areas and the relationship was statistically significant $(p<0.001)$. Other factors significantly associated with IPV in pregnancy were age $(p=0.008)$, religion $(p<0.001)$, SEC class of both partners, witnessing IPV during childhood $(p<0.001)$, and consumption of alcohol and illicit substances by both partners $(p<0.001)$. Factors such as length of relationship, parity, and knowledge of IPV were not significantly associated with IPV (Table 5).

\section{Discussion}

Intimate partner violence is a reality that affects people in all walks of life and has remained a problem of public health importance. In this study, the mean age of the respondents was $29.09 \pm 4.99$ years, which is similar to what was reported in a study on workplace violence and sexual harassment in Ethiopia [29]. The similarity observed in both studies could be attributed to the fact that more than half of the respondents were below 30 years of age; moreover, up to $47.3 \%$ of them were within the age group of 20-29 years. More than two-thirds of the respondents in this study were Hausa Muslims, and this could be a reflection of the study area which predominantly comprises of Muslims and people of Hausa ethnicity. However, there is also a notably significant proportion of other tribes including the Yoruba and Igbo 
TABLE 1: Sociodemographic characteristics of respondents.

\begin{tabular}{|c|c|}
\hline Variables & $\begin{array}{l}\text { Frequency } \\
\quad(\%)\end{array}$ \\
\hline \multicolumn{2}{|l|}{ Age group (years) } \\
\hline$<20$ & $13(5.0)$ \\
\hline $20-29$ & $123(47.3)$ \\
\hline $30-39$ & $122(46.9)$ \\
\hline $40-49$ & $2(0.8)$ \\
\hline Mean & $29.09 \pm 4.99$ \\
\hline \multicolumn{2}{|l|}{ Marital status } \\
\hline Married & $259(99.6)$ \\
\hline Widowed & $1(0.4)$ \\
\hline \multicolumn{2}{|l|}{ Type of marriage } \\
\hline Monogamous & $217(83.5)$ \\
\hline Polygamous & $43(16.5)$ \\
\hline \multicolumn{2}{|l|}{ Religion } \\
\hline Islam & $198(76.2)$ \\
\hline Christianity & $61(23.5)$ \\
\hline Others & $1(0.4)$ \\
\hline \multicolumn{2}{|l|}{ Tribe } \\
\hline Hausa & $169(65.0)$ \\
\hline Yoruba & $50(19.2)$ \\
\hline Igbo & $21(8.1)$ \\
\hline Fulani & $20(7.7)$ \\
\hline \multicolumn{2}{|l|}{ Place of residence } \\
\hline Urban & $190(72.1)$ \\
\hline Rural & $70(26.9)$ \\
\hline \multicolumn{2}{|l|}{ Level of education of wife } \\
\hline University/HND graduate & $92(36.4)$ \\
\hline Diploma/NCE/SSCE & $34(13.1)$ \\
\hline Completed primary school/JSS & $47(18.1)$ \\
\hline Primary school not completed/ & $13(5.0)$ \\
\hline Qur'anic school only/none & $74(28.5)$ \\
\hline \multicolumn{2}{|l|}{ Level of education of husband or partner } \\
\hline University/HND graduate & $140(53.8)$ \\
\hline Diploma/NCE/SSCE & $55(21.2)$ \\
\hline Completed primary school/JSS & $49(18.8)$ \\
\hline Primary school not completed/ & $6(2.3)$ \\
\hline Qur'anic school only/none & $10(3.8)$ \\
\hline \multicolumn{2}{|l|}{ Occupation of wife } \\
\hline $\begin{array}{l}\text { Senior civil servant/professional/manager/ } \\
\text { contractor/large scale business }\end{array}$ & $63(24.2)$ \\
\hline $\begin{array}{l}\text { Intermediate school civil servant/secondary } \\
\text { school teacher }\end{array}$ & $14(5.4)$ \\
\hline Junior secondary school teacher/driver/artisan & $53(20.4)$ \\
\hline Petty trader/labourer/messenger & $12(4.6)$ \\
\hline Subsistent farmer/student/full-term house wife & $118(45.4)$ \\
\hline \multicolumn{2}{|l|}{ Occupation of husband/partner } \\
\hline $\begin{array}{l}\text { Senior civil servant/professional/manager/ } \\
\text { contractor/large scale business }\end{array}$ & $133(51.5)$ \\
\hline $\begin{array}{l}\text { Intermediate school civil servant/ } \\
\text { secondary school teacher }\end{array}$ & $39(15)$ \\
\hline
\end{tabular}

TABle 1: Continued.

\begin{tabular}{lc}
\hline Variables & $\begin{array}{c}\text { Frequency } \\
(\%)\end{array}$ \\
\hline Junior secondary school teacher/driver/artisan & $42(16.2)$ \\
Petty trader/labourer/messenger & $38(14.6)$ \\
Subsistent farmer/student/full-term house wife & $7(2.7)$ \\
Wife's SEC & \\
Upper class & $96(36.9)$ \\
Middle class & $41(15.8)$ \\
Lower class & $123(47.3)$ \\
Husband/partner's SEC & \\
Upper class & $170(65.4)$ \\
Middle class & $53(20.4)$ \\
Lower class & $37(14.2)$ \\
\hline
\end{tabular}

and this is understandable as this study was conducted in a urban area which is mainly cosmopolitan.

Those who had completed their tertiary education constituted the highest proportion of the respondents (96 (36.4\%)), and this is probably because the study was conducted in a teaching hospital located within the metropolis; moreover, most people who belong to the high echelon of society preferred sending their wives to the teaching hospital for ANC where we have an array of specialist gynecologists. The findings were comparable to studies carried out within and outside of Nigeria $[2,11,30]$.

Majority of the respondents $(92.3 \%)$ were aware of what IPV is, and a greater proportion of them $102(39.2 \%)$ heard about it from the media. This high level of awareness observed is not surprising because this study also revealed that up to $99 \%$ of the respondents had good knowledge of IPV. Studies conducted in Delta State and Abuja, Nigeria, also made similar observations $[31,32]$.

Most of the respondents had correct responses to the question regarding forms of violence; however, questions relating to physical violence had more correct responses compared to questions on psychological and sexual violence. The high level of knowledge of the physical form of IPV observed in this study and other studies may likely be attributed to the influence of culture on the perception of what constitutes violence, such that most women especially in Africa only consider the physical form of IPV as violence but do not consider some other forms of IPV as violence. As a result of cultural factors, women tend to believe once you are married, it is the man's right to demand for sex at any time and forcing his spouse to have sexual intercourse is not considered as sexual violence; even the Nigerian law does not clearly state anything regarding issues like marital rape [33-35]. Studies in rural Ethiopia and America on cultural difference in knowledge of violence among Hispanics, African American, and Polish residents also made similar observations where most of the women considered only physical violence as IPV $[36,37]$. This underscores the need to educate women on other forms of IPV in a culturally acceptable manner. In terms of overall knowledge of IPV, this study observed that up to $99 \%$ of the respondents had 
TABLE 2: Knowledge of IPV among pregnant women.

\begin{tabular}{|c|c|}
\hline Variables & $\begin{array}{l}\text { Frequency } \\
\quad(\%)\end{array}$ \\
\hline \multicolumn{2}{|l|}{ Have you heard of IPV? } \\
\hline Yes & $239(92.3 \%)$ \\
\hline No & $20(7.7)$ \\
\hline \multicolumn{2}{|c|}{ Source of information on IPV } \\
\hline Media & $102(39.2 \%)$ \\
\hline Personal experience & $34(13.1 \%)$ \\
\hline Hospital/health worker & $1(0.4 \%)$ \\
\hline Lecture/seminar & $104(40 \%)$ \\
\hline \multicolumn{2}{|c|}{ IPV is a serious public health issue } \\
\hline Yes & $253(97.3 \%)$ \\
\hline No & $7(2.7 \%)$ \\
\hline \multicolumn{2}{|c|}{$\begin{array}{l}\text { Slapping, kicking dragging, beating, choking, } \\
\text { pushing, etc., are examples of IPV }\end{array}$} \\
\hline Yes & $250(96.2 \%)$ \\
\hline No & $10(3.8)$ \\
\hline \multicolumn{2}{|c|}{$\begin{array}{l}\text { Forcing partner to have sex when he/she does not } \\
\text { want to }\end{array}$} \\
\hline Yes & $227(87.3 \%)$ \\
\hline No & $33(12.7 \%)$ \\
\hline \multicolumn{2}{|c|}{$\begin{array}{l}\text { Forcing partner to do something sexual that he/she } \\
\text { finds degrading or humiliating }\end{array}$} \\
\hline Yes & $219(84.2 \%)$ \\
\hline No & $41(15.8 \%)$ \\
\hline \multicolumn{2}{|c|}{$\begin{array}{l}\text { Belittling or humiliating a partner in front of other } \\
\text { people }\end{array}$} \\
\hline Yes & $230(88.5 \%)$ \\
\hline No & $30(11.5 \%)$ \\
\hline \multicolumn{2}{|c|}{$\begin{array}{l}\text { Restricting a partner from contact with family or } \\
\text { friends }\end{array}$} \\
\hline Yes & $243(93.5 \%)$ \\
\hline No & $17(6.5 \%)$ \\
\hline \multicolumn{2}{|c|}{ Denial of food and other nutritional substance } \\
\hline Yes & $231(88.8 \%)$ \\
\hline No & $29(11.2)$ \\
\hline
\end{tabular}

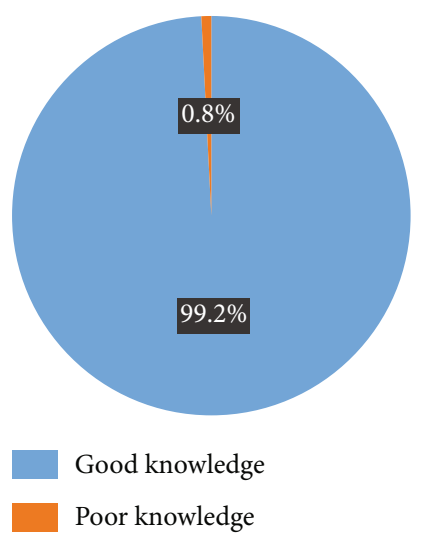

FIGURE 1: Knowledge of intimate partner violence.

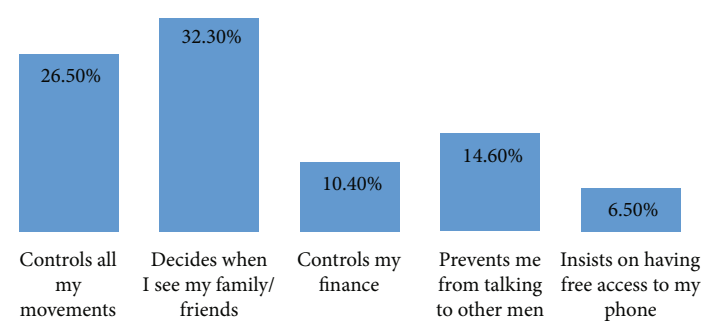

FIgURE 2: Controlling behavior of partner (multiple responses considered).

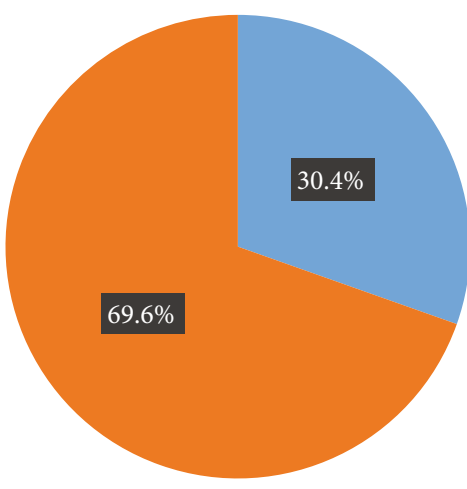

Experienced IPV

Did not experience IPV

FIGURE 3: Lifetime prevalence of IPV during pregnancy.
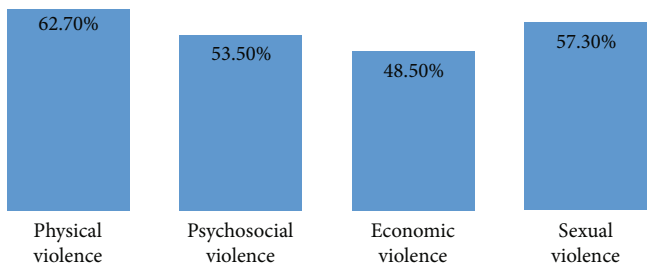

FIgURE 4: Forms of IPV in pregnancy experienced by respondents (multiple responses considered).

good knowledge of IPV and this is much higher than the $72 \%$ and $75.7 \%$ reported in studies conducted in Jos and Kano Nigeria, respectively [38, 39]. This high proportion of respondents with good knowledge of IPV is not surprising because more than half of the respondents had up to tertiary level education.

Controlling behaviors reported by respondents include having to always ask for permission before seeing friends and family (32.6\%) and partners controlling all their movements, including controlling their finances (10.6\%). These findings are similar to what was reported in a study involving the use of secondary data from NDHS 2008 but lower than the $43.3 \%$ reported in another study conducted in Kano $[27,40]$. Controlling behavior by the husband/partner has been shown to be associated with both physical and sexual IPV [41, 42], and it is a reflection of the increased vulnerability to abuse by women residents in societies that validate a male-dominated family structure and social order and 
TABLE 3: Experience of women on various forms of IPV during pregnancy.

\begin{tabular}{l}
\hline Variables \\
Have you ever experienced IPV during pregnancy? \\
Yes \\
No \\
If yes, during which pregnancy was IPV \\
experienced? \\
First \\
Subsequent pregnancies \\
Was the pregnancy you experienced IPV desired and \\
planned for? \\
Yes \\
No
\end{tabular}

Number of times you ever experienced IPV during pregnancy?

Once

Twice

More than twice

Frequently

Magnitude of intimate partner violence during pregnancy compared to outside pregnancy

More frequent

Less

Same

$26(32.9 \%)$

$53(67.1 \%)$

$217(83.5 \%)$

$43(16.5 \%)$

$13(16.5 \%)$

$9(11.4 \%)$

$5(6.3 \%)$

$52(65.8 \%)$

$7(8.8 \%)$

$44(55.7 \%)$

$28(35.4 \%)$

Type of physical violence experienced during pregnancy

Pushing, shoving, pulling hair, or slapping

Kick on the abdomen, beating, or choking

Thrown something at, attempted burning

Has your partner ever insulted or made you feel bad?

Yes

No

Did your partner ever belittle or humiliate you before people

Yes

No

Has your partner/husband ever taken your earnings or savings against your will?

$$
\text { Yes }
$$

No

$48(18.5 \%)$

$212(81.5 \%)$

Has your partner ever refused to give you money for household expenses?

Yes

No

Have you ever been forced by your partner to have sexual intercourse by threatening you or

withholding certain things?

Yes

$39(15 \%)$

No

$221(85 \%)$

Do you agree to have sexual intercourse with your partner when you do not want to?

Yes

$110(42.3 \%)$

$150(57.7 \%)$
TABLE 4: Reactions of respondents following their experience of IPV during pregnancy.

\begin{tabular}{lc}
\hline Variables & Frequency (\%) \\
\hline If you have experienced IPV during pregnancy, & \\
what did you do? & $46(61.3 \%)$ \\
$\quad$ Nothing & $19(25.3 \%)$ \\
$\quad$ Reported him to relations & $10(13.3 \%)$ \\
$\quad$ Quit relationship & \\
If nothing, why? & $35(77.8 \%)$ \\
$\quad$ Fear & $10(22.2 \%)$ \\
I forgave him & \\
Did you seek for medical care following the effect & \\
of the violence? & \\
$\quad$ Yes & $58(79.5 \%)$ \\
No & $15(20.5 \%)$ \\
If yes, how were you managed? & \\
In-patient & $29(50.9 \%)$ \\
$\quad$ Out-patient & $28(100 \%)$ \\
If you did not seek for medical care why? & \\
Due to fear & \\
Do you think IPV during pregnancy should be \\
encouraged by the society?
\end{tabular}

encourage men to exercise control over women. This finding is in support of the feminist theory [43] and is also in favor of the hypothesis that controlling behavior is associated with increased likelihood of violence, most likely acting as a precursor to violence.

Close to one-third of the respondents had experienced IPV at least in one of their pregnancies, with a significant proportion $(65.8 \%)$ of women reporting frequent exposure 
TABLE 5: Factors associated with IPV during pregnancy.

\begin{tabular}{|c|c|c|c|}
\hline \multirow[t]{2}{*}{ Variables } & \multicolumn{2}{|c|}{$\begin{array}{l}\text { Ever experienced } \\
\text { IPV during } \\
\text { pregnancy? }\end{array}$} & \multirow[t]{2}{*}{ Test statistic } \\
\hline & Yes & No & \\
\hline \multicolumn{4}{|l|}{ Age (years) } \\
\hline$<20$ years & $0(0)$ & $13(100)$ & $X^{2}=11.105$ \\
\hline 20-29 years & $47(38.2)$ & $76(61.8)$ & \\
\hline $30-39$ years & $32(26.2)$ & $90(73.8)$ & $p=0.008$ \\
\hline $40-49$ years & $0(0)$ & $2(100)$ & \\
\hline \multicolumn{4}{|l|}{ Tribe } \\
\hline Hausa & $25(14.8)$ & $144(85.2)$ & $X^{2}=71.286$ \\
\hline Yoruba & $31(62.0)$ & $19(38.0)$ & \\
\hline Igbo & $6(28.6)$ & $15(71.4)$ & $p<0.001$ \\
\hline Fulani & $17(85.0)$ & $3(15.0)$ & \\
\hline \multicolumn{4}{|l|}{ Religion } \\
\hline Islam & $39(19.7)$ & $159(80.3)$ & $X^{2}=45.44$ \\
\hline Christianity & $39(63.9)$ & $22(36.1)$ & $p<0.001$ \\
\hline Others & $1(100)$ & $0(0)$ & $P<0.001$ \\
\hline \multicolumn{4}{|l|}{ Place of residence } \\
\hline Urban & $40(21.1)$ & $150(78.9)$ & $X^{2}=29.055$ \\
\hline Rural & $39(55.7)$ & $31(44.3)$ & $p<0.001$ \\
\hline \multicolumn{4}{|l|}{ Wife's SEC } \\
\hline Upper class & $5(5.2)$ & $91(94.8)$ & $X^{2}=47.49$ \\
\hline Middle class & $15(36.6)$ & $26(63.4)$ & $p<0.001$ \\
\hline Lower class & $59(48.0)$ & $64(52.0)$ & $P<0.001$ \\
\hline \multicolumn{4}{|c|}{ Husband/partner's SEC } \\
\hline Upper class & $36(21.2)$ & $134(78.8)$ & $X^{2}=19.709$ \\
\hline Middle class & $25(47.2)$ & $28(52.8)$ & $n<0001$ \\
\hline Lower class & $18(48.6)$ & $19(51.4)$ & $P<0.001$ \\
\hline \multicolumn{4}{|l|}{ Parity } \\
\hline Primi & $5(14.3)$ & $30(85.7)$ & $X^{2}=5.054$ \\
\hline Multipara & $58(32.4)$ & $121(67.6)$ & $n=0.076$ \\
\hline Grand multipara & $16(34.8)$ & $30(65.2)$ & $P=-0.070$ \\
\hline \multicolumn{4}{|c|}{ Length of relationship } \\
\hline 1-5 years & $19(26.4)$ & $53(73.6)$ & $X^{2}=3.820$ \\
\hline $6-10$ years & $46(35.9)$ & $82(64.1)$ & $p=0.149$ \\
\hline$>10$ years & $14(23.3)$ & $46(76.7)$ & $P=0.17$ \\
\hline \multicolumn{4}{|c|}{$\begin{array}{l}\text { Witnessed IPV during your } \\
\text { childhood? }\end{array}$} \\
\hline Yes & $30(88.2)$ & $4(11.2)$ & $X^{2}=61.887$ \\
\hline No & 49 (21.7) & $177(78.3)$ & $p<0.001$ \\
\hline \multicolumn{4}{|c|}{$\begin{array}{l}\text { Who chose your partner for } \\
\text { you? }\end{array}$} \\
\hline Parents & $16(34.8)$ & $30(65.2)$ & $X^{2}=0.511$ \\
\hline Myself & $63(29.4)$ & $151(70.6)$ & $p=0.483$ \\
\hline \multicolumn{4}{|c|}{$\begin{array}{l}\text { Who takes the most } \\
\text { important decision for your } \\
\text { family? }\end{array}$} \\
\hline My partner & $16(100)$ & $0(0)$ & $X^{2}=52.342$ \\
\hline
\end{tabular}

TABLE 5: Continued.

\begin{tabular}{|c|c|c|c|}
\hline \multirow[t]{2}{*}{ Variables } & \multicolumn{2}{|c|}{$\begin{array}{l}\text { Ever experienced } \\
\text { IPV during } \\
\text { pregnancy? }\end{array}$} & \multirow[t]{2}{*}{ Test statistic } \\
\hline & Yes & No & \\
\hline Both of us & $58(24.3)$ & $181(75.7)$ & \multirow{2}{*}{$p<0.001$} \\
\hline In-laws & $5(100)$ & $0(0)$ & \\
\hline \multicolumn{4}{|c|}{ Do you consume alcohol? } \\
\hline Yes & $8(88.9)$ & $1(11.1)$ & $X^{2}=15.085$ \\
\hline No & $71(28.3)$ & $180(71.7)$ & $p<0.001$ \\
\hline
\end{tabular}

Does your partner consume alcohol?

$\begin{array}{lccc}\text { Yes } & 41(95.3) & 2(4.7) & X^{2}=102.795 \\ \text { No } & 38(17.5) & 179(82.5) & p<0.001\end{array}$

Do you use illicit drugs/substances?

$$
\begin{array}{cccc}
\text { Yes } & 29(96.7) & 1(3.3) & X^{2}=71.403 \\
\text { No } & 49(21.4) & 180(78.6) & p<0.001
\end{array}
$$

Does your partner use illicit drugs/substances?

$$
\begin{array}{lccc}
\text { Yes } & 6(85.7) & 1(14.3) & X^{2}=10.411 \\
\text { No } & 73(28.9) & 180(71.1) & p=0.004
\end{array}
$$

Is your partner very jealous?

\begin{tabular}{lccc} 
Yes & $75(32.5)$ & $156(67.5)$ & $X^{2}=3.894$ \\
No & $4(14.3)$ & $24(85.7)$ & $p=0.052$ \\
Knowledge of IPV & & & \\
Good knowledge & $2(100)$ & $0(0)$ & $p=0.091$ \\
Poor knowledge & $76(29.7)$ & $180(70.3)$ & (Exact) \\
\hline
\end{tabular}

by their husband/male partner. This is in tandem with the finding from the study by Sigalla et al. in Tanzania where a prevalence of IPV in pregnancy of $30 \%$ was observed [44].

However, the prevalence of IPV recorded in our study is lower than what was reported from similar studies on magnitude and correlates of IPV in Ethiopia [45] and in Southwest Nigeria [46], where the lifetime prevalence of intimate partner violence was $70 \%$. The lower prevalence in this study could probably be due to the fact that this study looked at IPV in pregnancy as against the other studies that looked at lifetime prevalence both in and outside pregnancy. Despite the fact that the prevalence of IPV observed in this study is lower than the lifetime prevalence observed in other studies, it still carries huge public health implications because IPV in pregnancy has been shown to be associated with a higher rate of maternal and foetal outcomes [19, 47-50].

Of the various forms of IPV experienced during pregnancy, physical violence was the most common (62.7\%). Studies conducted in Kano and Oyo States reported lower prevalences $[40,51]$. However, higher rates of physical violence were also reported in studies conducted in southwest Ethiopia, Tanzania, eastern Nigeria, Bangladesh, Ukraine, and Peru $[45,50-54]$. 
Close to two-thirds of the study subjects opined that they received kicks on the abdomen, beating, and choking whereas a smaller proportion (17.8\%) said pushing, shoving, pulling of hair, and slapping were the forms of physical violence that they experienced. Empirical evidence has shown that such kicks to the pregnant abdomen do result in devastating effects on both the mother and the foetus; in a Tanzanian study, 23 and $38 \%$ of all women exposed to physical violence during pregnancy suffered blows to the abdomen [50] which may lead to placental damage, rupture of the membrane, and consequently premature uterine contractions [55].

These forms of physical violence were also reported from other studies within and outside Nigeria; for example, in a study conducted in Southwest Nigeria, the major types of physical violence experienced were being slapped (27.2\%), being kicked (14.4\%), and being hit (13.4\%), [56] and in Malawi 20\% reported being pushed, shaken, slapped, or punched [57]. A little above half (57.3\%) of the respondents experienced sexual violence during pregnancy. A World Health Organization multicountry study observed that the lifetime prevalence of sexual violence by an intimate partner in most sites studied was between 10 and 50\% [5]. Sexual violence was reportedly lower compared to physical violence probably because of the fact that issues of sex are still regarded as a taboo and should not be openly discussed $[35,36]$. In a similar study carried out in Lima, Peru, the lifetime prevalence of sexual violence was $8.7 \%$ [58].

Regarding the action taken by respondents after exposure to IPV, up to $61.3 \%$ of them said they did nothing and the reason given by $77.8 \%$ of them was that it was because of fear of repercussions. In a study on the disclosure of IPV conducted in Lagos, slightly more than half (54\%) of the respondents agreed that they would not disclose their experiences of violence to anyone [59]. Traditionally, women especially in rural areas are often encouraged to stay in abusive relationships without disclosing their experiences to anyone, due to the strong cultural belief that a woman's place is with her husband and also because divorced and separated women are not held in high social esteem compared to women who remain in marriage. This could well be the reasons why most felt reporting was unnecessary and couples should rather handle their own issues as culture and religion advocates that women should learn to endure and be patient in all circumstances. Anecdotal evidence in most parts of Nigeria showed that mothers of victims of IPV would ask them to remain in their husbands' homes saying "after all, we the mothers went through the same experiences in the hands of your fathers".

Regarding factors associated with IPV during pregnancy, this study revealed that the tribe of the respondents was significantly associated with IPV; up to $62 \%$ of those who are of the Yoruba tribe had experienced IPV, whereas only $14.8 \%$ from among the Hausa tribe experienced it. This is not surprising because according to the NDHS 2013 report, IPV in pregnancy is higher in Southwest Nigeria (where Yoruba is the predominant tribe) than in Northwest Nigeria which has the highest proportion of people of the Hausa tribe in the country [27]. This may not be related to the fact that the sociocultural milieu of Sokoto State, the study area, does not encourage the reporting of incidents of IPV. Also, more than half $(55.7 \%)$ of those who lived in the rural areas experienced IPV compared to those living in urban areas and this is similar to what was observed in other studies from Southwest Nigeria [23, 46].. However, findings from a study in Southwest Nigeria and Ethiopia were at variance with what was obtained in this study, where those with formal education formed a larger proportion of those experiencing abuse $[45,59]$. This variation shows that violence cuts across all groups, and the belief that only women who are uneducated face violence may be exaggerated because there are many other factors that contribute to women's risk of intimate partner violence. Other factors significantly associated with IPV in pregnancy are age, religion, witnessing IPV during childhood, and consumption of alcohol and illicit substances by both partners. Evidence has shown that IPV occurred more among those whose partners consumed alcohol [51]. This suggests that if alcohol consumption by male intimate partners can be well controlled, then the prevalence of IPV may also be reduced significantly. Factors such as length of relationship, parity, and knowledge of IPV were not significantly associated with IPV.

Findings from this study buttresses the fact that the occurrence of IPV is an interplay of different factors which may solely be due to differences in individuals, culture, and the society, as what is obtained in one setting, even though it may be similar, may not apply in another.

\section{Conclusion}

A very high proportion of the respondents had good knowledge of IPV, and about one-third of them had experienced IPV in pregnancy. A sizeable number of the respondents that experienced IPV did nothing about it, mainly due to fear of what might follow. This fear may not be unrelated to the sociocultural milieu of the study area where religion controls the social lives of the inhabitants especially the womenfolk. Factors associated with IPV include tribe, place of residence, level of education of partners, and alcohol consumption. Increased public awareness on the dangers inherent in IPV should be intensified while governments at all levels and law enforcement agencies should ensure that the perpetrators are made to face the law and stiffer penalties are meted out to perpetrators of IPV, while at the same time encouraging victims of IPV to speak out regardless of length of onset. Women's organizations must be in the vanguard for the fight against IPV and to come up with avenues and measures to break the cycle of silence and to fight for the rights of women, while also rehabilitating victims of such acts.

5.1. Study Limitations. Intimate partner violence is a culturally sensitive issue in this part of the world and victims are afraid of retributions, hence some may inadvertently hoard important information. We tried from the onset to allay their fears and assure them of the confidentiality of any information divulged to the researchers. 


\section{Data Availability}

Data/results and narratives are in tandem with what the authors have inputed.

\section{Conflicts of Interest}

The authors declare that they have no conflicts of interest.

\section{References}

[1] World Health Organization, "Responding to intimate partner violence and sexual violence against women: WHO clinical and policy guidelines," NLM classification: HV 6625, 2013, May 2015, https://www.who.int/iris/bitstream/10665/85240/ 1/9789241548595_eng.pdf.

[2] World Health Organization, Understanding and addressing violence against women. Publication No., WHO/RHR/12.36, 2012, June 2015, https://www.who.int/iris/bitstream/10665/ 77432/1/WHO_RHR_12.36_eng.pdf.

[3] E. Abama and M. A. Chris, "Violence against women in Nigeria: how the Millennium Development Goals addresses the challenge," The Journal of Pan African Studies, vol. 3, pp. 23-34, 2009.

[4] National Institute of Justice, "Intimate partner violence," 2007, January 13, 2019 https://www.nij.gov/topics/crime/ intimatepartner-violence/Pages/welcome.aspx.

[5] C. Garcia-Moreno, H. A. F. M. Jansen, M. Ellsberg, L. Heise, and C. H. Watts, "Prevalence of intimate partner violence: findings from the WHO multi-country study on women's health and domestic violence," The Lancet, vol. 368, no. 9543, pp. 1260-1269, 2006.

[6] World Health Organization, "Violence: A Public Health Priority," in WHO Global Consultation on Violence and Health, World Health Organization, Geneva, 1996, document WHO/EHA/SPI.POA.2.

[7] E. G. Krug, J. A. Mercy, L. L. Dahlberg, and A. B. Zwi, “The World report on violence and health," The Lancet, vol. 360, no. 9339, pp. 1083-1088, 2002.

[8] O. A. Uthman, S. Lawoko, and T. Moradi, "Factors associated with attitudes towards intimate partner violence against women: a comparative analysis of 17 sub-Saharan countries," BMC International Health and Human Rights, vol. 9, no. 1, article 14, 2009.

[9] L. E. Okenwa, S. Lawoko, and B. Jansson, "Exposure to intimate partner violence amongst women of reproductive age in Lagos, Nigeria: prevalence and predictors," Journal of Family Violence, vol. 24, no. 7, pp. 517-530, 2009.

[10] O. I. Fawole, A. L. Aderonmu, and A. O. Fawole, "Intimate partner abuse: wife beating among civil servants in Ibadan, Nigeria," African Journal of Reproductive Health, vol. 9, no. 2, pp. 54-64, 2005.

[11] N. Ameh and M. A. Abdul, "Prevalence of domestic violence amongst pregnant women in Zaria, Nigeria," Annals of African Medicine, vol. 3, no. 1, pp. 4-6, 2004.

[12] A. Gyuse and A. P. Ushie, "Pattern of domestic violence among pregnant women in Jos, Nigeria," South African Family Practice, vol. 51, no. 4, pp. 343-345, 2009.

[13] G. Lewis, "Statistics: incidence and prevalence of domestic violence," 2007, https://www.wewillspeakout.org/wp-content/ uploads/2013/03/domestic-violence.
[14] E. I. Mbadugha, "Intimate partner violence and sexual violence against women: any end in sight?," International journal of Medicine and Biomedical Research, vol. 5, no. 1, pp. 9-18, 2016.

[15] N. Linos, N. Slopen, S. V. Subramanian, L. Berkman, and I. Kawachi, "Influence of community social norms on spousal violence: a population-based multilevel study of Nigerian women," American Journal of Public Health, vol. 103, no. 1, pp. 148-155, 2013.

[16] A. Bandura, Social Learning Theory, General Learning Press, New York, NY, 1977, http://www.asecib.ase.ro/mps/ Bandura_SocialLearningTheory.pdf.

[17] M. A. A. Nunes, S. Camey, C. P. Ferri, P. Manzolli, C. N. Manenti, and M. I. Schmidt, "Violence during pregnancy and newborn outcomes: a cohort study in a disadvantaged population in Brazil," The European Journal of Public Health, vol. 21, no. 1, pp. 92-97, 2011.

[18] S. E. Sanchez, A. V. Alva, G. Diez Chang et al., "Risk of spontaneous preterm birth in relation to maternal exposure to intimate partner violence during pregnancy in Peru," Maternal and Child Health Journal, vol. 17, no. 3, pp. 485492, 2013.

[19] D. K. Kaye, F. M. Mirembe, G. Bantebya, A. Johansson, and A. M. Ekstrom, "Domestic violence during pregnancy and risk of low birthweight and maternal complications: a prospective cohort study at Mulago Hospital, Uganda," Tropical Medicine and International Health, vol. 11, no. 10, pp. 1576-1584, 2006.

[20] K. M. Devries, S. Kishor, H. Johnson et al., "Intimate partner violence during pregnancy: analysis of prevalence data from 19 countries," Reproductive Health Matters, vol. 18, no. 36, pp. 158-170, 2010.

[21] S. Ahmed, M. A. Koenig, and R. Stephenson, "Effects of domestic violence on perinatal and early-childhood mortality: evidence from North India," American Journal of Public Health, vol. 96, no. 8, pp. 1423-1428, 2006.

[22] R. M. Laisser, L. Nyström, H. I. Lugina, and M. Emmelin, "Community perceptions of intimate partner violence - a qualitative study from urban Tanzania," BMC women's Health, vol. 11, no. 1, article 13, 2011.

[23] A. O. Fatusi and O. I. Alatise, "Intimate partner violence in IleIfe, Nigeria: women's experiences and men's perspectives," Gender and Behaviour, vol. 4, no. 2, pp. 764-781, 2007.

[24] M. Rani, S. Bonu, and N. Diop-Sidibe, "An empirical investigation of attitudes towards wife-beating among men and women in seven sub-Saharan African countries," African Journal of Reproductive Health, vol. 8, no. 3, pp. 116-136, 2004.

[25] World Health Organization, Understanding and Addressing Violence against Women: Intimate Partner Violence during Pregnancy, World Health Organization, 2012, WHO_RHR_ 11_.35_eng.pdf.

[26] S. Alhabib, U. Nur, and R. Jones, "Domestic violence against women: systematic review of prevalence studies," Journal of Family Violence, vol. 25, no. 4, pp. 369-382, 2010.

[27] National Population Commission-NPC/Nigeria and ICF, Nigeria Demographic and Health Survey 2018, NPC and ICF, Abuja, Nigeria and Rockville, MD, USA, 2019.

[28] M. O. Araoye, Research Methodology with Statistics for Health and Social Sciences, Nathadex Publishers, Ilorin, 2004.

[29] J. Marsh, S. Patel, B. Gelaye et al., "Prevalence of workplace abuse and sexual harassment among female faculty and 
staff," Journal of Occupational Health, vol. 51, no. 4, pp. 314-322, 2009.

[30] L. Heise, "Violence against women: global organizing for change," in Future Interventions with Battered Women and their Families, J. L. Edleson and Z. C. Eisikovits, Eds., pp. 733, CA, Sage Publications, Thousand Oaks, 1996.

[31] V. Awusi, V. Okeleke, and B. Ayanwu, "Prevalence of domestic violence during pregnancy in Oleh, a suburban Isoko community, Delta State, Nigeria," Benin Journal of Postgraduate Medicine, vol. 11, no. 1, 2009.

[32] E. R. Efetie and H. A. Salami, "Domestic violence on pregnant women in Abuja, Nigeria," Journal of Obstetrics and Gynaecology, vol. 27, no. 4, pp. 379-382, 2007.

[33] K. A. Oyediran and U. C. Isiugo-Abanihe, "Perceptions of Nigerian women on domestic violence: evidence from 2003 Nigeria Demographic and Health Survey," African Journal of Reproductive Health, vol. 9, no. 2, pp. 38-53, 2005.

[34] O. Ogunsiji, L. Wilkes, D. Jackson, and K. Peters, "Suffering and smiling: West African immigrant women's experience of intimate partner violence," Journal of Clinical Nursing, vol. 21, no. 11-12, pp. 1659-1665, 2012.

[35] E. Robson, "Wife seclusion and the spatial praxis of gender ideology in Nigerian Hausaland," Gender, Place \& Culture, vol. 7, no. 2, pp. 179-199, 2000.

[36] W. Shanko, M. Wolday, N. Assefa, and A. R. Aro, "Domestic violence against women in Kersa, Oromia region, eastern Ethiopia," Eastern Mediterranean Health Journal, vol. 19, no. 1, pp. 18-23, 2013.

[37] K. Wytrykowska, "Cultural Differences in Knowledge and Reporting of Domestic Violence, [M. S. thesis]," Criminal Justice submitted to Central Connecticut State University, 2011.

[38] E. Ochai, "Knowledge and attitude of women towards intimate partner violence: a study of women in Tudun Wada community in Jos," Injury Prevention, vol. 16, article A229, Supplement 1, 2010.

[39] A. Salaudeen, T. M. Akande, O. I. Musa, J. O. Bamidele, and F. A. Oluwole, "Assessment of violence against women in Kano metropolis, Nigeria," The Nigerian Postgraduate Medical Journal, vol. 17, no. 3, pp. 218-222, 2010.

[40] T. S. Tanimu, S. Yohanna, and S. Y. Omeiza, "The pattern and correlates of intimate partner violence among women in Kano, Nigeria," African Journal of Primary Health Care and Family Medicine, vol. 8, no. 1, pp. e1-e6, 2016.

[41] A. J. Gage and P. L. Hutchinson, "Power, control and intimate partner sexual violence in Haiti," Archives of Sexual Behavior, vol. 35, no. 1, pp. 11-24, 2006.

[42] G. Krantz and N. D. Vung, "2The role of controlling behaviour in intimate partner violence and its health effects: a population based study from rural Vietnam," BMC Public Health, vol. 9, no. 1, article 143, Article ID 1546, 2009.

[43] T. K. Shackelford and A. T. Goetz, "Men's sexual coercion in intimate relationships: development and initial validation of the sexual coercion in intimate relationships scale," Violence and Victims, vol. 19, no. 5, pp. 541-556, 2004.

[44] G. N. Sigalla, D. Mushi, D. W. Meyrowitsch et al., "Intimate partner violence during pregnancy and its association with preterm birth and low birth weight in Tanzania: a prospective cohort study," PLoS One, vol. 12, no. 2, article e0172540, 2017.

[45] K. Deribe, B. K. Beyene, A. Tolla, P. Memiah, S. Biadgilign, and A. Amberbir, "Magnitude and correlates of intimate partner violence against women and its outcome in Southwest Ethiopia," PloS One, vol. 7, no. 4, article e36189, 2012.

[46] M. O. Balogun, E. T. Owoaje, and O. I. Fawole, "Intimate partner violence in southwestern Nigeria: are there rural-urban differences?," Women \& Health, vol. 52, no. 7, pp. 627-645, 2012.

[47] B. Parker, J. McFarlane, and K. Soeken, "Abuse during pregnancy: effects on maternal complications and birth weight in adult and teenage women," Obstetrics and Gynecology, vol. 84, no. 3, pp. 323-328, 1994.

[48] H. Blencowe, S. Cousens, M. Z. Oestergaard et al., "National, regional, and worldwide estimates of preterm birth rates in the year 2010 with time trends since 1990 for selected countries: a systematic analysis and implications," The Lancet, vol. 379, pp. 2162-2172, 2012.

[49] B. Mahenge, S. Likindikoki, H. Stöckl, and J. Mbwambo, "Intimate partner violence during pregnancy and associated mental health symptoms among pregnant women in Tanzania: a cross-sectional study," BJOG: An International Journal of Obstetrics \& Gynaecology, vol. 120, no. 8, pp. 940-947, 2013.

[50] H. Stockl, C. Watts, and J. K. Kilonzo Mbwambo, "Physical violence by a partner during pregnancy in Tanzania: prevalence and risk factors," Reproductive Health Matters, vol. 18, no. 36, pp. 171-180, 2010.

[51] O. Yusuf, O. Arulogun, O. Oladepo, and F. Olowokeere, "Physical violence among intimate partners in Nigeria: a multi level analysis," Journal of Public Health and Epidemiology, vol. 3, no. 5, pp. 240-247, 2011.

[52] A. L. Ilika, "Women's perception of partner violence in a rural Igbo community," African Journal of Reproductive Health, vol. 9, no. 3, pp. 77-88, 2005.

[53] M. J. Hindin, S. A. Kishor, and L. Donna, Intimate partner violence among couples in 10 DHS countries: predictors and health outcomes, Macro International Inc., Calverton, MD, 2008.

[54] L. Ismayilova and N. El-Bassel, "Prevalence and correlates of intimate partner violence by type and severity: populationbased studies in Azerbaijan, Moldova, and Ukraine," Journal of Interpersonal Violence, vol. 28, no. 12, pp. 2521-2556, 2013.

[55] J. Campbell, S. Torres, J. Ryan et al., "Physical and nonphysical partner abuse and other risk factors for low birth weight among full term and preterm Babies: A Multiethnic CaseControl Study," American Journal of Epidemiology, vol. 150, no. 7, pp. 714-726, 1999.

[56] E. Owoaje and F. Olaolorun, "Women at risk of physical intimate partner violence: a crosssectional analysis of a low-income community in Southwest Nigeria," Journal of Reproductive Health, vol. 16, no. 1, pp. 43-51, 2012.

[57] S. Bazargan-Hejazi, S. Medeiros, R. Mohammadi, J. Lin, and K. Dalal, "Patterns of intimate partner violence: a study of female victims in Malawi," Journal of Injury and Violence Research, vol. 5, no. 1, pp. 38-50, 2013.

[58] M. T. Perales, S. M. Cripe, N. Lam, S. E. Sanchez, E. Sanchez, and M. A. Williams, "Prevalence, types, and pattern of intimate partner violence among pregnant women in Lima, Peru," Violence Against Women, vol. 15, no. 2, pp. 224-250, 2009.

[59] L. E. E. Okenwa, S. Lawoko, and B. Jansson, "Factors associated with disclosure of intimate partner violence among women in Lagos, Nigeria," Journal of Injury and Violence Research, vol. 1, no. 1, pp. 37-47, 2009. 